\title{
Internship Orientation: An Essential Facilitatory Bridging Step for Medical Students
}

\author{
Rajesh Kathrotia, Farhanul Huda ${ }^{1}$, Shalinee Rao ${ }^{2}$, Anupama Bahadur ${ }^{3}$, Ravi Kant ${ }^{4}$, Manisha Naithani ${ }^{5}$ \\ Department of Physiology, ${ }^{1}$ General Surgery, ${ }^{2}$ Pathology \& Advanced Center of Continuous Professional Development, ${ }^{3}$ Obstetrics \& \\ Gynecology, ${ }^{4}$ Director, ${ }^{5}$ Biochemistry, All India Institute of Medical Sciences, Rishikesh, Uttarakhand, India
}

\begin{tabular}{|c|}
\hline Access this article online \\
\hline Website: www.avicennajmed.com \\
\hline DOI: 10.4103/ajm.ajm_202_20 \\
\hline Quick Response Code: \\
\hline
\end{tabular}

\begin{abstract}
Background: Internship is a facilitatory period that hones skills and helps in the evolution of a qualified medical student to a competent doctor. The feeling of a final year student joining as a fresh intern after successfully completing the final professional examination will be directionless without a bridging initiative through a buffer program. Fresh interns need to be oriented to the fundamentals of working effectively with a patient as a whole and not as a separate discipline. This study was done to evaluate the effectiveness of the internship orientation program and to assess the feedback of participants about this program. Methodology: This was a study conducted on 235 freshly joined medical interns. The process included evaluation of a wellstructured seven-day orientation program by prevalidated structured Multiple Choice Questions (MCQs) and feedback. Results: All interns performed satisfactorily in the post-test with a mean score of $74.13 \pm 7.18$. Post-test scores were highest for procedure skills and communication skills, including medical ethics. Overall, $232(99 \%)$ of interns responded that the program was useful and it successfully enhanced their clinical skills; $221(94 \%)$ of interns expressed that the content of the program was excellent to good; and $228(97 \%)$ of interns felt that the method used for training was appropriate. Interns also documented that there were a few new skills that were acquired by attending this program. Conclusion: There is an unmet need for an internship orientation program across all medical colleges to lay a strong foundation for naive interns. Based on the results, we recommend an internship orientation program for a smooth and swift transition from that of a medical student to professional life. It will orient the interns and lay the foundation for the next level of assignment in building their professional career.
\end{abstract}

Key words: Internship orientation program, medical interns, skills, transition

Key Messages: Internship orientation programs are recommended for a smooth and swift transition from that of a medical student to professional life.

\section{INTRODUCTION}

An internship is a delicate and yet essential transition phase for a medical graduate, a period during which a medical student metamorphoses into a complete doctor. During the period, an undergraduate student technically learns various disciplines in different years as per the curriculum. Immediately after successful completion of his/ her final year, they are posted as interns in various departments to undergo one year of rigorous house surgeonship during which they

Address for correspondence: Dr. Farhanul Huda,

Department of General Surgery, All India Institute of Medical Sciences,

Rishikesh 249203, Uttarakhand, India.

E-mail: farhanul1973huda@gmail.com participate in patient management and care. It has been seen that often the interns are oblivious of what is expected out of them and work aimlessly. Gaps in knowledge and suboptimal practical skills of fresh interns have resulted in medical

This is an open access journal, and articles are distributed under the terms of the Creative Commons Attribution-NonCommercial-ShareAlike 4.0 License, which allows others to remix, tweak, and build upon the work non-commercially, as long as appropriate credit is given and the new creations are licensed under the identical terms.

For reprints contact: reprints@medknow.com

Cite this article as: Kathrotia R, Huda F, Rao S, Bahadur A, Kant R, Naithani M. Internship orientation: An essential facilitatory bridging step for medical students. Avicenna J Med 2021;11:77-83. 
errors and have compromised patient safety. ${ }^{[1]}$ In addition, team work, hospital guidelines and policies are subjects that are untouched during medical schooling. ${ }^{[2]}$ Therefore, it becomes essential that prior to fresh interns starting work in a hospital, they should be primed about it. This training should ideally comprise sessions to make them aware of their roles and responsibilities, to gain knowledge about hospital policies and guidelines. They should also be made to do core procedural skills on task trainers under supervision so that they become capable of working independently in the future without compromising patient safety. ${ }^{[1]}$ The focus should be on explaining to them the need or reason with logic to know these facts, just like any other fresh recruit in the hospital.

Twelve months of training as an intern is important, as it poses challenges to these bright young minds in terms of learning to work in a multidisciplinary team under stressful conditions. They have to interact with various health-care workers and also communicate with patients, which requires a good amount of interpersonal skills to work effectively and empathetically even in complex situations. While working in the hospital they are exposed to certain circumstances with variable ethical and legal issues. An insight into real working conditions and day-to-day scenarios can prepare these naive minds to deal with and respond to such situations in the future. ${ }^{[3]}$ Besides exposure to patient care, it brings clarity to their minds and helps them to discharge their duties to the best of their capabilities. This includes writing prescriptions, patient progress notes, and discharge summary and following other hospital guidelines.

In our institute, an internship orientation program is organized regularly for fresh interns to acquaint them about hospital policies and goals as well as to enhance their skills required for assisting in patient care. The current study was conducted to determine the usefulness of the internship orientation program for the fresh batch of medical interns. The objectives of this study were to:

1. Assess the effectiveness of the internship orientation module as an induction course for fresh interns.

2. Evaluate intern perception and key learning points on the internship orientation modules.

3. Identify sessions that should become part of the undergraduate curriculum based on feedback.

\section{MATERIALS AND METHODS}

A seven-day well-structured orientation program for freshly joined interns is held every year at the Advanced Center of Continuous Professional Development (CPD) in All India Institute of Medical Sciences, Rishikesh, Uttarakhand,
India [Tables 1 and 2]. The program includes brief lectures and active teaching learning methods such as group discussions, role-plays, video demonstrations, and skill training on task trainers. Interns are apprised of their roles and responsibilities. Adult learning principles are used in a highly interactive and nonthreatening environment.

Evaluation of the overall program was done by a prevalidated structured Post-Course Test through Multiple Choice Questions (MCQs) on each topic covered in the orientation program. Pretest and post-test assessment was conducted for sessions on Hand Hygiene and Biomedical Waste (BMW) Management as well as Occupational Hazards and Vaccination. Only posttest was conducted for the rest of the sessions due to time constraints. Interns were requested to fill the feedback form in which they gave their opinion on the overall quality of the program, time given to each session, content of the program, trainee and resource faculty integration, delivery of the content, and enhancement of skills after attending this training program. A few open-ended questions were also included, for which they were asked to give a descriptive response.

Skill stations [Tables 1 and 2] were arranged and delivered through small group teaching of six to eight interns per batch. Procedural stations were delivered with good interaction by the instructor. Emphasis was given to discussing real-life situations with complexities that can be involved and how to deal with them. The five-step approach of psychomotor teaching was practiced for imparting specific skills (Step 1, conceptualization; Step 2, demonstration through visualization; Step 3, deconstruction; Step 4, comprehension through verbalization by trainee; Step 5 , performance by the trainee with correction and reinforcement). Each intern was allowed to practice adequately until the competency was achieved or until the intern himself or herself felt confident of performing the task independently.

\section{RESULTS}

The internship orientation program was conducted in January 2019 for 107 interns and again in January 2020 for 128 interns.

\section{Effectiveness of internship orientation program}

Effectiveness of the internship orientation module as an induction course for fresh interns was assessed by a post-test conducted at the end of the course by objective assessment through MCQs. The distribution of questions as per topics covered in the post-test is displayed in Figure 1.

The majority of interns scored between $65 \%$ and $85 \%$ in the post-test, with an overall mean score of $74.13 \pm 7.18$ (Range 


\begin{tabular}{|c|c|c|}
\hline S. no & Day & Session \\
\hline 1 & Day I & Role and responsibilities of an intern \\
\hline 2 & & International patient safety goals \\
\hline 3 & & Rational use of drug and adoption of safety measures; essential drugs \\
\hline 4 & & Measures of safety in surgical procedures; How to avoid mishaps /Errors in medical-surgical procedures \\
\hline 5 & & $\begin{array}{l}\text { Hand hygiene and Biomedical Waste Management } \\
\text { (universal safety precautions: Handwashing, personal protective equipment; hospital infection control committee) }\end{array}$ \\
\hline 6 & Day 2 & Documentation records and maintenance of patient files/ record \\
\hline 7 & & The patient care-essential policy adopted currently at our institute \\
\hline 8 & & Pharmacy at our institute \\
\hline 9 & & Legal aspects in medical documentation, informed consent: Filling of death certificate \\
\hline 10 & & Pharmacovigilance-our responsibility \\
\hline II & & Occupational health hazard and vaccination \\
\hline 12 & Day 3 & Professional ethics in patient care \\
\hline 13 & & Doctor-patient relationship \\
\hline 14 & & Communication skills \\
\hline 15 & & Professionalism and alternative medicine \\
\hline 16 & & Confidentiality \\
\hline 17 & & Breaking bad news \\
\hline 18 & & Informed consent \\
\hline 19 & & Humanities in medicine \\
\hline 20 & Day 4 & The rationale of ordering investigations \\
\hline 21 & & Government Insurance Scheme-Ayushman Bharat \\
\hline 22 & & Filling of investigation request forms and critical alerts \\
\hline 23 & & Sample collection and transport-haematology clinical pathology, biochemistry; cytology and histopathology \\
\hline 24 & & Sample collection and transport tests in microbiology \\
\hline 25 & & Know your attitude and perception for effective management of stress/ conflict and interpersonal relationship \\
\hline 26 & $\begin{array}{l}\text { Day } 5 \\
\text { and } 6\end{array}$ & $\begin{array}{l}\text { Basic life support (BLS) American Heart Association certified } \\
\text { Procedural/examination skill training }\end{array}$ \\
\hline 28 & Day 7 & Request for blood products from the blood bank \\
\hline 29 & & Hemovigilance transfusion protocols \\
\hline 30 & & Dealing with work stress \\
\hline 31 & & Alumni-message from senior batches \\
\hline 32 & & Assessment \\
\hline 33 & & Feedback \\
\hline
\end{tabular}

of score shown in [Figure 2]). Topic-wise performance in the post-test is shown in Table 3.

Post-test scores were found to be highest for the procedure skills and communication skills, including medical ethics followed by documentation and medical records and patient safety. They scored lowest in the topic of ordering investigation and blood products [Table 3].

Analysis of training on occupational hazards showed a statistically significant improvement in post-test scores, $12.83 \pm 1.63$, compared with pretest scores, $6.70 \pm 1.84$ $(P<0.001)$, as shown in Figure 3.

Analysis of training on hand hygiene and BMW showed statistically significant improvement in post-test scores, $18.26 \pm 1.57$, compared with pretest scores, $13.3 \pm 2.48$ $(P<0.001)$, as shown in Figure 4.

\section{Interns' perception of orientation program}

On analysis of interns' perception about the internship orientation module and key learning points learnt, 225 (96\%) interns expressed that the time allotted for training was adequate. According to 221 (94\%) interns, content of the
Table 2: Skill Stations with a hands-on learning experience for participants in the internship orientation program

Procedural/examination skill station

Gloving, gowning, and scrubbing techniques; aseptic techniques

Surgical knot tying

Male and female catheterization

Nasogastric (NG) tube insertion and tube feeding

Intravenous (IV) cannulation/ intramuscular (IM) injection

Arterial blood sampling

Abdominal paracentesis

Digital rectal examination (DRE) / prostate examination and breast

examination

Hemorrhage control

Wound dressing

program and delivery of content was excellent to good for the majority. The method used for training was considered appropriate by 228 (97\%), and the integration of trainee and resource faculty was scored as very good by $223(95 \%)$ of interns. Overall, 232 (99\%) of interns felt that there was skill enhancement after training and considered the training content very useful [Table 4].

About 89 (37.8\%) felt that basic life support was the most useful session, whereas $50(21 \%)$ considered surgical and 


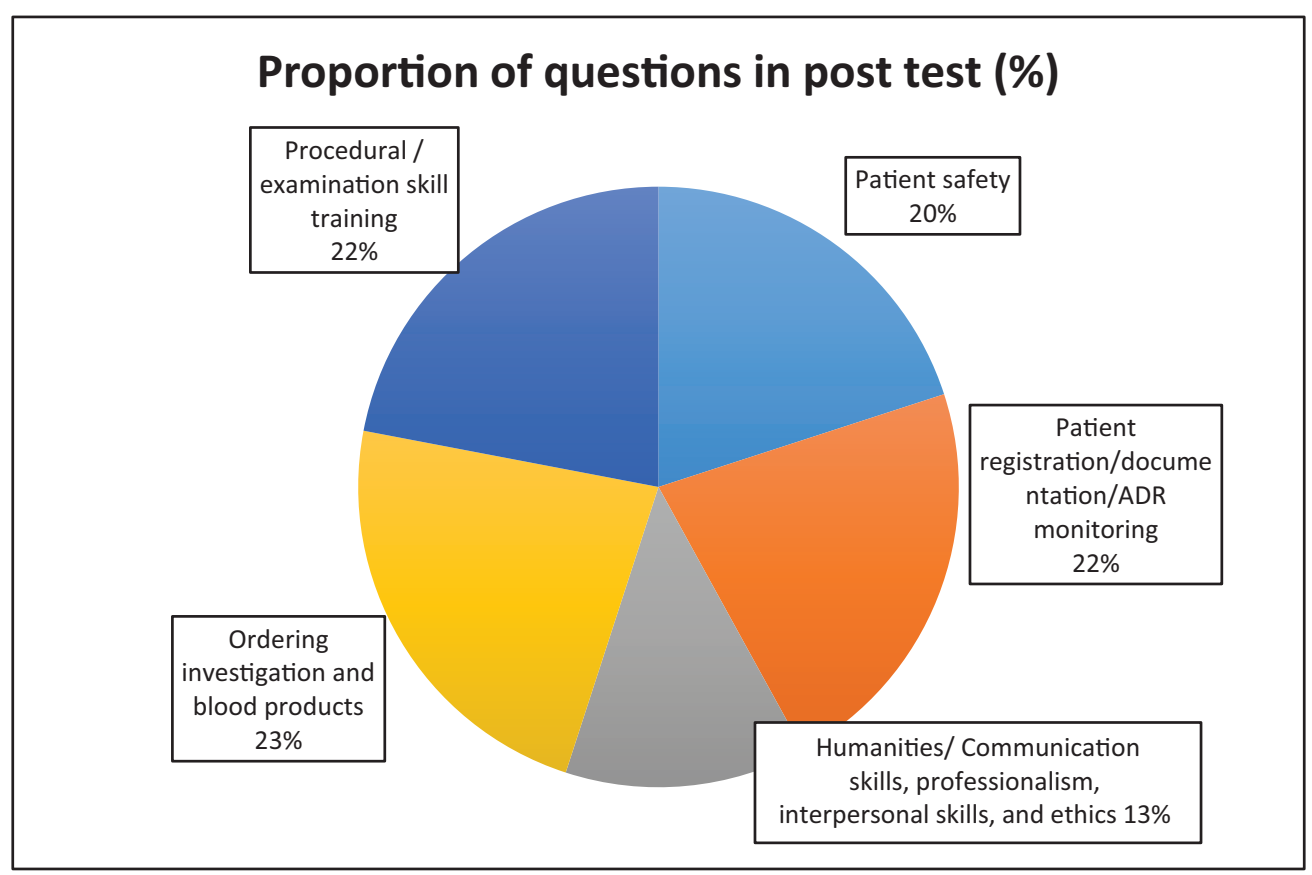

Figure 1: Distribution of topics in the post-test

\begin{tabular}{lc}
\hline Table 3: Post-test scores as per the topic distribution \\
\hline Topic & Scores (\%) \\
\hline Patient safety & 76 \\
Patient registration/documentation/ADR monitoring & 75 \\
Humanities/communication skills, professionalism, & 82 \\
interpersonal skills, and ethics & \\
Ordering investigation and blood products & 69 \\
Procedural/examination skill training & 84 \\
\hline
\end{tabular}

hands-on skill training as the most useful. Other sessions that the participants found useful were soft skills, ethics, stress management, and BMW management [Figure 5].

In their feedback, a few questions were open-ended and interns expressed their views and opinions, as depicted in Table 5.

\section{New skills learnt by interns}

Interns documented that there were few new skills acquired by them through this program module and they expressed that these should be included as a part of the undergraduate medical curriculum. The newly acquired skills enumerated by them included:

- Basic life support

- Humanities/ communication skills, professionalism, internal personal relations, and ethics

- Stress management

\section{DISCUSSION}

During the medical undergraduate teaching and clinical postings, students are taught the nuances of history taking and

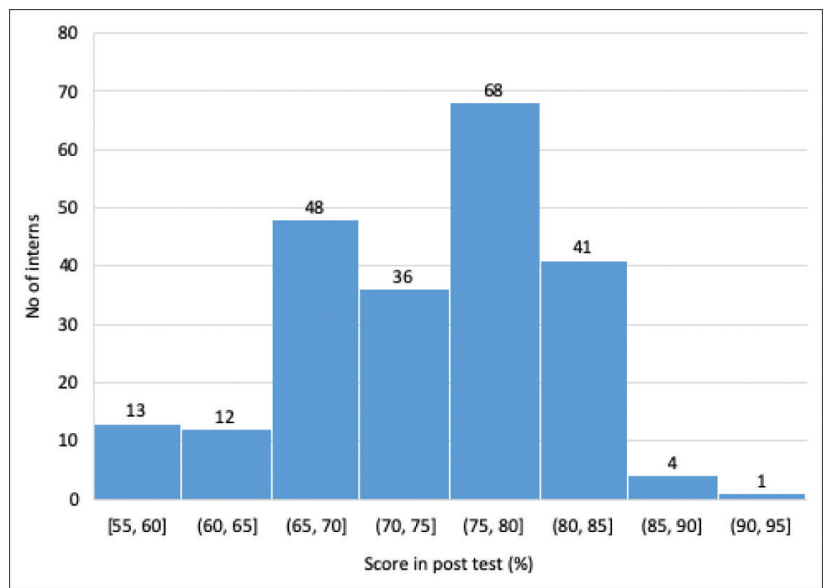

Figure 2: Histogram showing the frequency of total scores in post-test

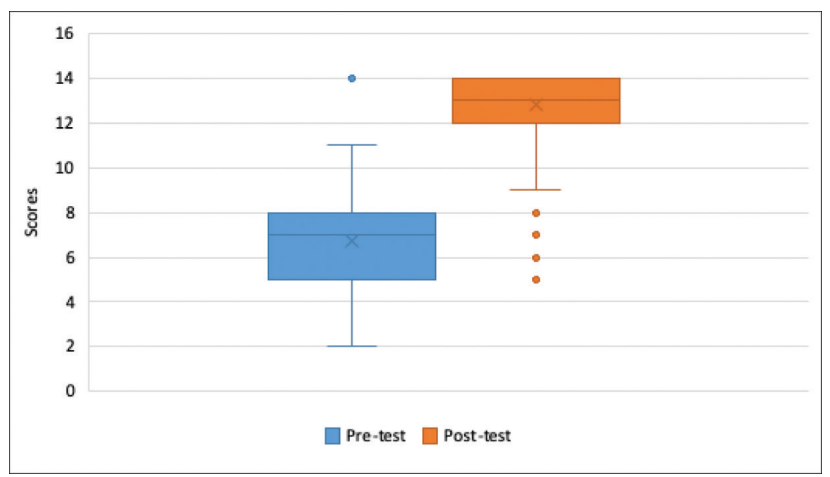

Figure 3: Pretest and post-test scores for training on occupational hazard $(n=232)$

examination; however, their training occurs in a controlled environment and the focus of the students while learning is to attain passing grades (assessment-driven learning). 


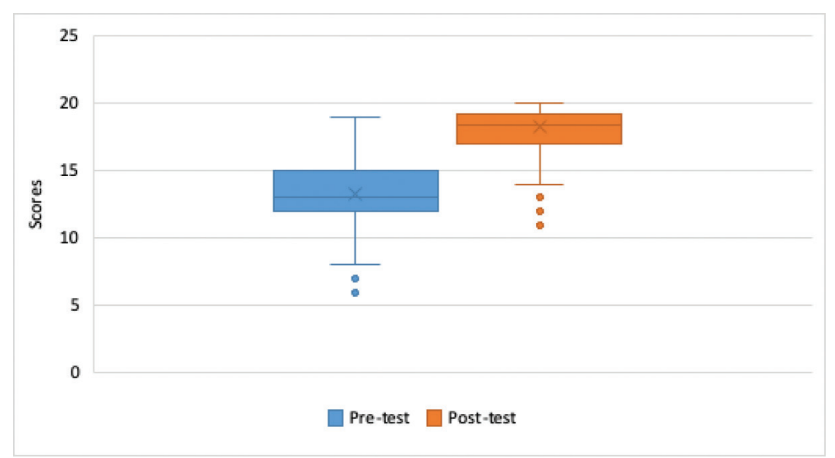

Figure 4: Pretest and post-test scores for training on hand hygiene and BMW management $(n=232)$

\begin{tabular}{|c|c|c|}
\hline S. no. & Items & $n(\%)$ \\
\hline I. & Time accorded for training & $225(95.7 \%)$ Adequate \\
\hline 2. & Content of program & $\begin{array}{l}\text { II } 5 \text { (48.\%) Excellent } \\
\text { I06 (45\%) Good } \\
\text { I4 (6\%) Average }\end{array}$ \\
\hline 3. & Delivery of relevant content & $\begin{array}{l}94(40 \%) \text { Excellent } \\
124(52.7 \%) \text { Good } \\
14(6 \%) \text { Average } \\
3(1.2 \%) \text { Poor }\end{array}$ \\
\hline 4. & Method used for training & $228(97 \%)$ Appropriate \\
\hline 5. & $\begin{array}{l}\text { Trainee and resource faculty } \\
\text { integration }\end{array}$ & $\begin{array}{l}\text { I34 (57\%) Excellent } \\
89(37.8 \%) \text { Good } \\
12(5.1) \% \text { Average }\end{array}$ \\
\hline 6. & $\begin{array}{l}\text { Enhancement of skills after } \\
\text { attending this training }\end{array}$ & $232(99 \%)$ Yes \\
\hline 7. & $\begin{array}{l}\text { Usefulness of training } \\
\text { content }\end{array}$ & 232 (99\%) Yes \\
\hline
\end{tabular}

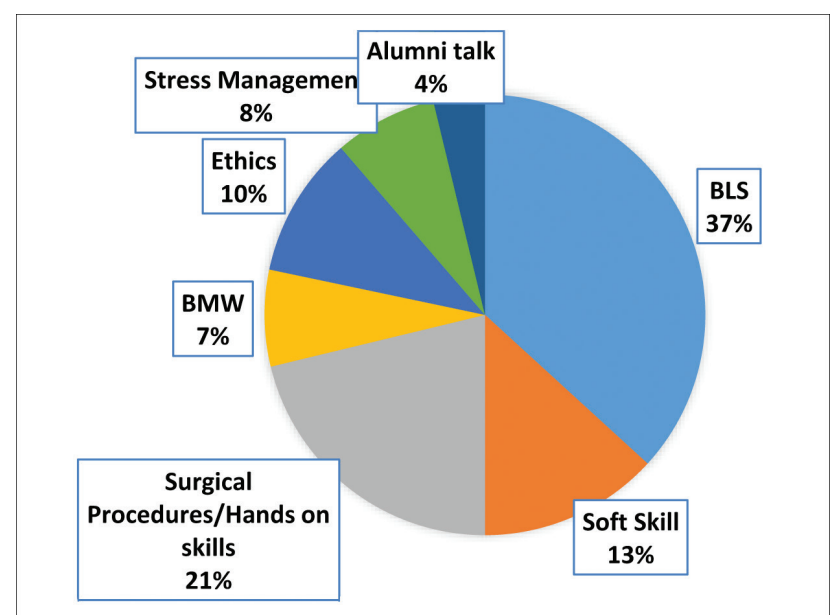

Figure 5: Most useful sessions according to interns during orientation program

Freedom to perform without the stressful influence of being assessed at each step is a major attributable factor in differentiating an undergraduate student's performance from that of an intern. The clinical approach of a student needs to be perfected with other attributes, culminating their transition into a practicing clinician with professional competence, good communication skills, stress-coping
Table 5: Concise qualitative feedback given by participants on take-home messages on internship orientation

- 'Hand hygiene is a powerful tool'

- 'Patient safety, priority along with self-care and motivation'

- 'Be a good human, see the patient as yourself'

- 'Good communication is important'

- 'Affective skills and ethics are equally important as are cognitive skills and knowledge'

- Medicine is a combination of science and art and this art in the form of soft skills helps you deal with situations in a better and more successful way'

- 'There is a lot beyond books'

- 'Try to treat the person, not the patient and try to cure the person, not the disease'

- 'A very beautifully structured program included every topic that is going to be an integral part of our training as an intern. Besides, I am looking forward to putting all of it into practical use'

- 'Maintain professionalism, the internship is all about practicing under supervision, ask seniors if any problem occurs'

- 'Interpersonal relationship and soft skills are very important'

- 'Learn to balance work life and personal life'

strategies, and ethical practice. It is imperative to sensitize these interns during the orientation program to bridge the gaps left during medical school teaching as well as enhance other required skills so that they become competent and are motivated to serve as able members of the health-care delivery system. ${ }^{[1]}$

The medical education has taken its skyrocketing development with a scaffold increase in medical graduates passing out every year as junior doctors. However, knowledge of performing basic procedural skills still receives widespread criticism. ${ }^{[4]}$ A study conducted by Hanson in Ireland revealed that $91 \%$ of newly graduating doctors were not prepared for the skills needed as an intern and training in personal characteristics, competence, and formal education during the internship period were found to be insufficient. ${ }^{[5]}$ It has also been a general observation that internship is a time utilized by interns to prepare for postgraduate entrance examinations at the expense of clinical work and hospital-based training, which is another concern requiring attention. The results of our study emphasize the valuable need to conduct an orientation program for interns before their clinical postings start to familiarize them with their roles and responsibilities regarding patient care.

A comprehensive orientation program prepares young graduates to work with confidence and contribute toward patient care while practicing patient safety goals, medical ethics, and communication skills, which were appropriately delivered to them through this program. The results of our study favor the need for structured pre-internship orientation and such programs can evoke further interest, increase efficiency, and hone communication skills. The findings of our study are in agreement with the results of 
the study conducted by the University of New South Wales, which evaluated a "Preparation for Internship" course. ${ }^{[6]}$

"There is a lot beyond books," a comment received from a participating intern sums up the importance of our internship orientation program. Open-ended feedback received from interns reveals the attainment of key learning points envisioned in this preinternship training program. The response of interns as main stakeholders on the content, quality, duration, and usefulness of the program reflects a good acceptance to the training modules. An overwhelming positive feedback for procedural stations, basic life support, and soft skills indicates their interest toward interactive and hands-on skill-based learning. The self-reporting of interns by feedback forms, pre- and post-test helps the teachers to predict deficiencies in educational opportunities and professional behavior of interns. It can help in drawing the attention of the policymakers for needful changes. ${ }^{[7]}$

Intervention through such tailored training programs on interns have been tried by a few educators, with encouraging results. ${ }^{[1,8]}$ These interventions are effective educational strategies to hone clinical skills and improve confidence in them. ${ }^{[9]}$ Satisfactory feedback and improvement in skills were reported by Mckenjee et al., who conducted a threeday training course of pre-interns on practical procedural skills, and Laack et al., who delivered a one-week simulated training course during internship. ${ }^{[1,3]}$ In contrast to these studies, our orientation course was a comprehensive program comprising many skill assets, ranging from documentation, patient safety policies, procedural skills to communication and team dynamics. Inconsistencies in educational content can be a possible threat to its total functionality, hence a uniformity in such programs is essential to ensure standard content and quality of training. ${ }^{[1]}$

A major concern in recent times is lack of knowledge of soft skills and this has escalated disrespect to the profession among the public, which has led to an increase in physical attacks on doctors in India. ${ }^{[10]}$ Thus, social and emotional skills are inseparable from cognitive skills and they are crucial for an effective thought process and decision making. ${ }^{[1]}$ Emotional intelligence (EI) skills such as communication, self-awareness, empathy, control on impulsiveness, the elevation of stress threshold, flexibility, and optimism are ways to cope with challenges and these essential abilities are required in the field of medicine. ${ }^{[12-14]}$ Educators have also emphasized that EI development should be included in medical school curricula. ${ }^{[15,16]}$ Hence, the emphasis has to be given not only to improve cognitive skills but also in developing good soft skills to improve Emotional Quotient (EQ) along with Intelligence Quotient (IQ). The Medical
Council of India (MCI) has recommended the Attitude, Ethics and Communication (AETCOM) Module and its implementation in all medical colleges in India. ${ }^{[17]}$

Stress management is another area that is often overlooked in the undergraduate curriculum. ${ }^{[18]}$ This should be included in the curriculum as well as pre-internship orientation to help the interns to cope with their mental strengths and to balance professional as well as personal life in this phase of transition. Basic life support, Humanities, interpersonal skills, ethics, and stress management are topics that should be included in the medical undergraduate curriculum, as expressed by interns in our study. Early acquisition of these skills would prime the medical students to be a better professional.

The MCI has made a Foundation Course mandatory for firstyear medical undergraduates as soon as the students join the Medical College regardless of which Medical Institute they join. ${ }^{[19]}$ Along the same lines, we recommend that all medical institutions adopt a holistic and comprehensive internship orientation program such as ours, to prepare the medical graduates for their assigned roles as interns.

\section{Limitations}

A pretest was not conducted for all delivered sessions due to time constraints in the seven-day training program and, hence, baseline knowledge and improvement in knowledge could not be evaluated for all content delivered. We could not take Faculty, Interns, Residents, and Patient feedback on their performance after attending this program to assess the real impact of this program.

\section{CONCLUSION}

The Internship Orientation Program acts as a seed initiative to sensitize fresh interns to the working environment of functioning as a qualified doctor. This program endows fresh interns with knowledge, skill, and confidence, which would support them in their transition from that of a student to professional life. It empowers them with a positive attitude toward patient care and improves their attitude toward the doctor-patient relationship as they step into the next phase, which is full of responsibilities and commitment. The inclusion of a comprehensive intensive transition course, prior to the commencement of internship is strongly recommended for an effective internship.

Financial support and sponsorship

Nil.

\section{Conflicts of interest}

There are no conflicts of interest. 


\section{References}

1. McKenzie S, Mellis C. The impact on internship of a tailored intern preparation package. Adv Med Educ Pract 2018;9:639-48.

2. Burford B, Whittle V, Vance GH. The relationship between medical student learning opportunities and preparedness for practice: A questionnaire study. BMC Med Educ 2014;14:223.

3. Laack TA, Newman JS, Goyal DG, Torsher LC. A 1-week simulated internship course helps prepare medical students for transition to residency. Simul Healthc 2010;5:127-32.

4. Durgawale PM, Durgawale PP. Medical education: Our current concern. Indian J Community Med 2006;31:121-2.

5. Hannon FB. A national medical education needs' assessment of interns and the development of an intern education and training programme. Med Educ 2000;34:275-84.

6. McNeil HP, Scicluna HA, Boyle P, Grimm MC, Gibson KA, Jones PD. Successful development of generic capabilities in an undergraduate medical education program. High Educ Res Dev 2012;31:525-39.

7. Berridge EJ, Freeth D, Sharpe J, Roberts CM. Bridging the gap: Supporting the transition from medical student to practising doctor-a two-week preparation programme after graduation. Med Teach 2007;29:119-27.

8. Wayne DB, Cohen ER, Singer BD, Moazed F, Barsuk JH, Lyons EA, et al. Progress toward improving medical school graduates' skills via a "boot camp" curriculum. Simul Healthc 2014;9:33-9.

9. Blackmore C, Austin J, Lopushinsky SR, Donnon T. Effects of postgraduate medical education "boot camps" on clinical skills, knowledge, and confidence: A meta-analysis. J Grad Med Educ 2014;6:643-52.
10. Nagpal N. Incidents of violence against doctors in India: Can these be prevented? Natl Med J India 2017;30:97-100.

11. Dolev N, Goldental N, Reuven-Lelong A, Tadmor T. The evaluation of emotional intelligence among medical students and its links with non-cognitive acceptance measures to medical school. Rambam Maimonides Med J 2019;10:e0010.

12. Bar-On R. The Bar-On model of emotional-social intelligence (ESI). Psicothema 2006;18:13-25.

13. Wagner PJ, Moseley GC, Grant MM, Gore JR, Owens C. Physicians' emotional intelligence and patient satisfaction. Fam Med 2002;34:7504.

14. Weng HC, Chen HC, Chen HJ, Lu K, Hung SY. Doctors' emotional intelligence and the patient-doctor relationship. Med Educ 2008;42:703-11.

15. Satterfield JM, Hughes E. Emotion skills training for medical students: A systematic review. Med Educ 2007;41:935-41.

16. Shakir HJ, Recor CL, Sheehan DW, Reynolds RM. The need for incorporating emotional intelligence and mindfulness training in modern medical education. Postgrad Med J 2017;93:509-11.

17. Attitude and Communication (AT-COM) Competencies for the Indian Medical Graduate. Reconciliation Board. Academic Committee of Medical Council of India. July 2015. https:/www.nmc.org.in/wp-content/ uploads/2020/01/AETCOM_book.pdf. [Last accessed on 2020 Oct 27].

18. Colley JM, Harris M, Hellyer P, Radford DR. Teaching stress management in undergraduate dental education: Are we doing enough? Br Dent J2018;224:405-7.

19. Foundation course for the undergraduate medical education program 2019. https://www.nmc.org.in/wp-content/uploads/2020/08/ FOUNDATION-COURSE-MBBS-17.07.2019.pdf. [Last accessed on 2020 Oct 27]. 